\title{
Effect of Polyester Fiber on Workability Property of High Strength Concrete
}

\author{
Mohsin Ali*, Aneel Kumar, Samar Hussain Rizvi, Sabir Ali, Israr Ahmed \\ Department of Civil Engineering, MUET, Jamshoro, Pakistan. \\ ${ }^{*}$ Corresponding author: engrmohsin34@gmail.com
}

\section{Abstract}

The utilization of (HSC) high strength concrete in the construction industry is increasing all over the world because it reduces the cross-section of structural members and increases floor area. High strength concrete can be produced by using high cement content with low $\mathrm{w} / \mathrm{c}$ ratio, mineral admixtures, and chemical admixture, and with suitable fiber. Nevertheless, in this research, HSC mix was achieved with the use of a special type BASF Master (M)/Polyheed 996 super-plasticizer based on polycarboxylic ether available in the market which reduced the $\mathrm{w} / \mathrm{c}$ of concrete mixes, albeit attaining adequate workability. Compressive strength, up to $63 \mathrm{Mpa}$ at 28 days, was achieved at slump value $178 \mathrm{~mm}$ by utilizing locally available materials like cement, sand, and coarse aggregates with a maximum $1.2 \%$ (by weight of cement) dosage of super-plasticizers. HSC has high workability, and to control the workability, different percentages of polyester fiber length $32 \mathrm{~mm}$ were also added to HSC. Polyester fiber controls the workability and improves the properties of HSC. There were four mixes designed with polyester fiber. The addition of polyester fiber content was $0.2 \%, 0.3 \%, 0.4 \%$, and $0.5 \%$ (by weight of cement) in HSC, and the slump value were $153 \mathrm{~mm}$, $127 \mathrm{~mm}, 102 \mathrm{~mm}$ and $76 \mathrm{~mm}$ respectively. It was observed that the usage of polyester fiber $(0.2 \%$ to $0.5 \%)$ decreases workability by $14 \%$ to $57 \%$ of HSC. Therefore, it was concluded that increasing the percentage of fiber decreases the slump to the required value.

Keywords-HSC, Aggregate, Superplasticizer, Polyester fiber, Workability

\section{Introduction}

$\mathrm{H}$ $\mathrm{SC}$ is a major construction material in concrete technology. It is economical, resourceful, and constructs structures that are not only strong, durable but also possess architectural polish, beauty, and style techniques as well. In last few decades, the main purpose of the construction industry was to achieve "high strength", but the present mega projects and high-rise structures need such type of concrete which have properties such as high workability, performance, and durability [1].

High-strength concrete is defined according to ACI363 R -92 as "concrete having a specified compressive strength of 8,000 psi (55 MPa) or greater"[2]. According to code UK, BS EN 206-1 defined highstrength concrete as "the concrete with compressive strength class greater than C50/60". Generally, concrete with a specified characteristic cube strength between 50 and $100 \mathrm{~N} / \mathrm{mm}^{2}$ is considered as high

ISSN: 2523-0379 (Online), ISSN: 1605-8607 (Print)

DOI: $10.52584 / Q R J .1802 .15$

This is an open access article published by Quaid-e-Awam University of Engineering Science \& Technology, Nawabshah, Pakistan under CC BY 4.0 International License. strength concrete[3]. The production of HSC and high-performance concrete is increasing due to its requirement in the construction of high-rise buildings and other mega projects. It is possible by utilizing large cement content, low water-cement ratio, mineral admixture, special types of fiber, and superplasticizer high range water reducer [4-7].However, the main concern is that cement industries are contributing to an increase of about $10 \%$ of carbon dioxide globally. To minimize the use of cement in the construction industry, it would be best to utilize other cement replacement materials such as rice husk ash, fly ash, silica fume, ground granulated blast furnace slag, and metakaolin and a special type of fibers (steel, glass, polypropylene and carbon fiber) in the construction industry which will be economical and eco-friendly [5][6] [8] [9]. The fresh and hardened properties of HSC are greatly influenced by these additives in comparison with conventional concrete. During the utilization of fibers in HSC, the fresh properties of concrete are a matter of great concern, as the addition of fibers in concrete reduces the flow-ability of concrete which causes a negative impact on workability because fiber 
hinders the mobility of fresh concrete [10-12]. The research is focused on the workability of HSC by utilizing polyester fiber. To check the effects of fiber on the workability of HSC, other factors such as size of aggregates, the texture of aggregates, size, shape, and type of fiber/c and type and dosage of chemical admixture [8][9][13] are considered.

The HSC not only has enhanced mechanical properties, but also high durability and reduced permeability. Thus, high-strength fiber reinforced concrete (HSFRC) is a composite material essentially consisting of conventional high-strength concrete reinforced by random dispersal of short, discontinues, and discrete fine fibers of specific geometry. This fiber was recently used in concrete as a structural reinforcement that controls small hair cracks and preserves the structural integrity and effects on the hardened properties. Therefore, the failure caused by the brittleness property of the concrete is prevented by the utilization of fiber [14-17].

From previous research studies, it is obvious that the behaviour of HSC is a brittle nature at ultimate loading. The addition of diligently spaced and evenly disseminated small fibers to concrete would act as a crack arrester and would substantially improve its mechanical behaviour and ductility. The utilization of fibers in HSC causes problems in attaining proper homogenous mix and humping in concrete which leads to honeycombed surfaces. In order to tackle this situation, many researchers are opting for different types of chemical admixture in the concrete mix which improves the fresh properties of concrete. These chemical admixtures not only improve workability, but also reduce the water demand of the concrete which helps to enhance the mechanical properties of concrete. Till now, there has been an extensive requirement for improving the properties of high-strength concrete regarding strength, toughness, flexibility, and execution as an underlying material with concrete to meet the prerequisites of the structure, climate, and different components. This is because the ordinary plain high strength concrete has high compressive strength, low tensile strength, flexibility, and minimum resistance from breaking and helpless protection from synthetic assault. Therefore, it is important to overcome these disadvantages of high-strength concrete. After continuous researches, researchers have concluded that the properties of HSC can be enhanced by different fibers known as fiber reinforced concrete. Selection of fiber is done based on different properties of fiber such as specific gravity, shape, length, water absorption, and tensile strength [16]. Hence, we have adopted a textile based fiber in this study. The effects of such textile based polyester fiber on the workability of HSC is not well investigated before.

For new materials such as high-strength glass fiber reinforced concrete, studies on mechanical behaviour are of paramount importance for initializing confidence in engineers. Kumar et. al. [18] in their experimental investigation found out that the fresh property of reinforced concrete gradually increased up to $45 \%$ by utilizing $0.33 \%$ and $0.45 \%$ contents of glass fiber along with ground granulated blast slag and then decreased [18]. Antonio et. al. [11] investigated the effects of fiber content on fresh properties of the concrete mixture. Ve-Be test and slump test were used to analyze the influence of fiber content in the concrete mixture. Experimental investigation showed that steel fiber used in concrete caused balling, crumbling problems and it also had a negative effect on workability. Moreover, it reduced the flowability of material because fiber worked as a barrier to coarse aggregates movement. These effects can be controlled by an increase in the mortar content and the initial slump could provide better workability conditions. Although results have shown that the Ve-Be test does not apply to conditions in which the concrete has great fluidity and having a slump greater than 100 $\mathrm{mm}$. This condition normally occurs for a low-volume of fibers, below $0.7 \%$ by volume $(55 \mathrm{~kg} / \mathrm{m} 3)$. On the contrary, for fiber contents above this value, the slump applicability is much more difficult [11].

Similar to high-strength steel fibers, other synthetic fibers having a low modulus of elasticity are utilized by researchers. In this context, Nyazi et. al. [10] investigated the effect of polypropylene on the strength and workability properties of normal concrete. Polypropylene fiber was used in the control mix at varying percentages from 0.06 to $2.16 \%$ at a w/c ratio of 0.45 . The slump value of $0 \%$ of polypropylene fiber was $40 \mathrm{~mm}$ and by increasing the percentages of polypropylene fiber, the slump value started decreasing. At $0.06 \%$ of polypropylene fiber, the slump value was $30 \mathrm{~mm}$. The slump value gradually decreased because of the hindrance in flowability of concrete caused by fiber in concrete ingredients [10]. Aswathy et. al [17] concluded that the normal concrete has good compression strength but it is weak in tension that is the reason for cracks in a concrete member. This is the reason why using polyester fiber can reduce cracks and deterioration, also increase the hardened properties of concrete, but the fresh property workability of polyester fiber reinforced concrete decreases with the increase of fiber [17]. Vagheesha et. al. [16] analyzed some drawbacks in conventional concrete and reduced these deficiencies by using polyester fiber Recron 3s. $0.2 \%$ to $1.8 \%$. The polyester fiber was used 
by the weight of cement. It showed that increasing the percentage of Recron 3S fiber in concrete, slump value gradually decreased due to water absorbed by Recron 3S fibers, thus causing a decrement in workability. The maximum workability was achieved at $0.2 \%$ of fiber and decreased as the percentage of fibers increased [16]. Indrajit et. al. [19] worked on M25, M30, M35, and M40 with class F fly ash at 50\%, $55 \%$ and $60 \%$ by weight of cement. They also used polyester fiber with the percentage of $0.25 \%$ by weight of cement and determined the different properties of concrete. The addition of polyester fiber increased the strength properties up to $15 \%$, but reduced the slump value from $110 \mathrm{~mm}$ to $90 \mathrm{~mm}$ in all mixes respectively [19]. Many industries generating plastic bottles that are biodegradable are also being used as fiber in concrete to enhance certain properties. Oscar et. al. [11] investigated the effect of recycled-bottle PET fiber on fiber reinforced concrete. Length of the fiber was $10 \mathrm{~mm}, 15 \mathrm{~mm}$, and $20 \mathrm{~mm}$, and volume fractions of $0 \%, 0.05 \%, 0.18 \%$, and $0.30 \%$ related to the volume of the concrete were used. It showed that the increment of recycled-bottle PET affects workability negatively. It decreases the slump value by $100 \mathrm{~mm}$, $155 \mathrm{~mm}, 70 \mathrm{~mm}$, and $50 \mathrm{~mm}$ respectively [12]. V. Pandey et. al. [20] investigated the effect of polyester polyethylene terephthalate (PET) fiber with varying percentage of fiber between $(0 \%, 0.25 \%$ and $0.3 \%)$. The reinforcement in concrete caused a reduction in slump value of M25 grade concrete and slump range was between 50-75 mm [20]. One of the methods of increasing workability is to use superplasticizer and air entraining agents [4][21]. The data shows that the increasing percentage of polyester fibers negatively affects the workability of concrete. The decrease in the flow-ability of concrete which assigns due to the existence of fibers in the concrete mix tending to lump on each other, ball, and absorb free water required for lubrication and paste formation. It is observed that the polyester fibers tend to introduce resistance to the mobility of concrete.

Our research aims to study the effects of the addition of polyester fiber with different contents $0.2 \%$, $0.3 \%, 0.4 \%$ and $0.5 \%$ (by weight of the cement) on the fresh properties of HSC.

\section{Experimental Investigation}

This research was conducted in the Concrete Research Laboratory of Civil Engineering Department, Mehran University of Engineering and Technology Jamshoro, Sindh by considering the main objectives of this research. Materials testing and conducting workability

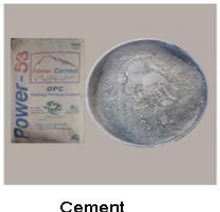

Cement
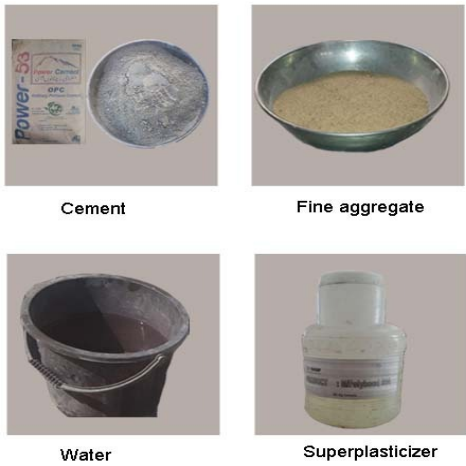

Fine aggregate

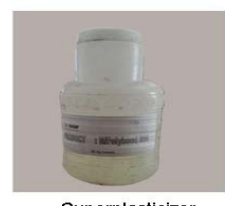

Superplasticizer

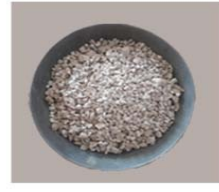

Coarse aggregate

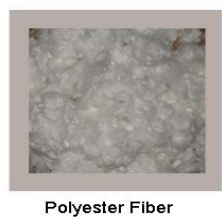

Fig. 1: Material used in the research work

of HSC tests at the prescribed form was a major part of the study. The main purpose of this research was to analyze the effect of polyester fiber on the workability of HSC. For this purpose, the sample of polyester fiber ware was brought from Bhanero Textile Mill Ltd., Kotri, Jamshoro, Sindh, Pakistan. The slump cone test was conducted on HSC by adding different percentages of polyester fiber $(0.2 \%, 0.3 \%, 0.4 \%, 0.5 \%)$ by weight of cement. The slump values of high-strength concrete containing different percentages of polyester fiber were noted.

\subsection{Materials}

In this experimental work, several materials were used to accomplish the purpose of this research work. The utilized materials and their sources are given in Table 1 and shown in Figure 1.

\subsection{Cement}

Cement is a fine, greyish powder. In this research work, the OPC type power-53 grade was used as the binder and to fill the pores left by fine aggregates and was obtained from a local construction shop. Different properties of power-53 grade cement tested included specific gravity, fineness, normal consistency, soundness, initial and final setting time. The compressive strength at 28 days were $3.14,97 \%, 0.33,2 \mathrm{~mm}, 72$ minutes, 185 minutes, and $42 \mathrm{MPa}$

\subsection{Fine Aggregate}

In this research, locally available sand is used (Bholari/Jamshoro area). The different tests were performed according to ASTM C128-04 such as fineness modulus 3.15 , water absorption $1.62 \%$, and specific gravity 2.69. The sieve analysis of sand was also performed according to BS882-1992, as shown in Figure 2. 


\begin{tabular}{|l|l|}
\hline Name of Material & Material source \\
\hline Cement & Power-53 OPC \\
\hline Fine Aggregate(Sand) & Sand( Bholari Jamshoro) \\
\hline Coarse Aggregate & Noori abad,Jamshoro,Sindh \\
\hline Water & Portable water available in concrete research laboratory civil department \\
\hline Super plasticizer (M/Polyheed 996) & BASF,Karachi, Sindh, Pakistan \\
\hline Polyester fiber & Bhanero textile mill ltd, Kotri, Jamshoro, Sindh, Pakistan \\
\hline
\end{tabular}

TABLE 1: Material used in mix design proportion

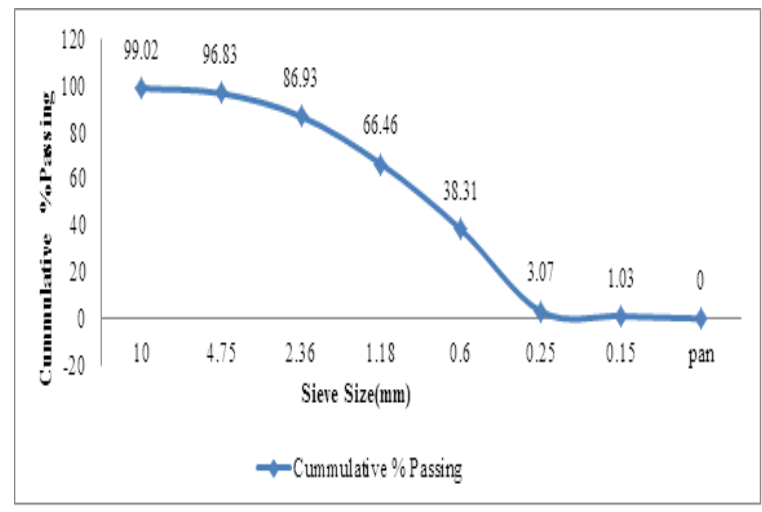

Fig. 2: Sieve analysis of fine aggregate (sand)

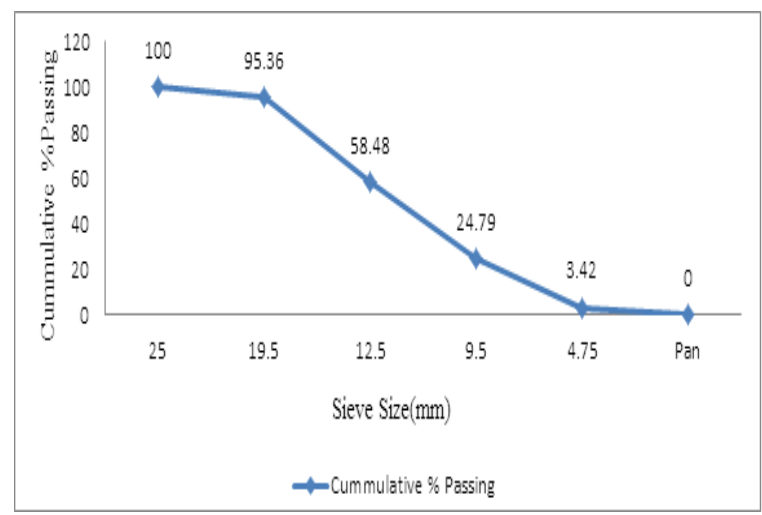

Fig. 3: Sieve analysis of coarse aggregate

\subsection{Coarse Aggregate}

These are the aggregates which retained on sieve size $4.75 \mathrm{~mm}$ and provide crushing strength to concrete. The maximum coarse aggregates size used in this research work is $20 \mathrm{~mm}(40 \%)$ and $13 \mathrm{~mm}(60 \%)$, and is collected from local quarrying site Nooriabad, Jamshoro, Sindh, Pakistan. The combined test results of $20 \mathrm{~mm}(40 \%)$ and $13 \mathrm{~mm}(60 \%)$ such as specific gravity, water absorption, bulk density, and fineness modulus were $2.7,0.53 \%, 1827 \mathrm{~kg} / \mathrm{m} 3$, and 2.87 , respectively. The sieve analysis of coarse aggregates is shown in Figure 3.

\subsection{Portable Water}

Water is a major constituent of concrete. Water, when mixed with cement, forms a paste that glues the aggregates together in concrete. It promotes the hydration of cement, resulting in the hardening of concrete. The water to cement $(\mathrm{w} / \mathrm{c})$ ratio is a key factor accountable for desired strength, durability, and workability. Generally, a lower $\mathrm{w} / \mathrm{c}$ ratio increases strength and durability, but decreases workability. Thus, to overcome this decreased workability, plasticizers are used. Water used for mixing the ingredients of concrete should be clean and free from salts, oils, acids, alkalis, etc. For the purpose of curing and producing high strength concrete, we used portable water containing a $\mathrm{PH}$ value equal to 7 .

\subsection{High Range Water Reducer}

This research work used superplasticizer high range water reducer M/Polyheed-996 developed based on polycarboxylic ether (PCE) by using Nanotechnology. As compared to another superplasticizer (Master Polyheed 3534 and Master Glenium 51), Mater Polyheed 996 is mostly used in the construction industry because of its higher ultimate strength and resistance to segregation. Its bleeding can be transported at lower pressure through pumps, is cheaper, and has the property to reduce water content greater than $20 \%$. Whereas, Master Polyheed 3534 is mostly advisable for precast concrete work. Superplasticizers conforming to ASTM-494 Type A, G, and F were used to increase the workability of $\mathrm{HSC}$ and reduce the $\mathrm{w} / \mathrm{c}$ ratio [9]. For reducing water content, the admixture is a superplasticizer. The main physical properties of Superplasticizer (Master Polyheed-996) specific gravity, chloride content, $\mathrm{PH}$ value, color, and alkali content, were $1.08 \pm 0.2 \mathrm{~kg}$ liter at $25^{\circ} \mathrm{C},<0.2 \%, \geq 6.0$, light brown liquid, and $0 \%$, respectively. It is cheaper and can reduce water content greater than 20\%. Master Polyheed 996 is a superplasticizer designed to produce good workable concrete and significantly enhances the properties of fresh and hardened concrete. The manufacturer dosage recommendation of BASF Master Polyheed 996 for normal concrete is $0.6 \%$ to $2.0 \%$, 


\begin{tabular}{|l|l|}
\hline Parameter & Description \\
\hline Colour & $\begin{array}{l}\text { straight smooth surface } \\
\text { White in colour }\end{array}$ \\
\hline Length & $32 \mathrm{~mm}$ \\
\hline Density & $1.29 \mathrm{~g} / \mathrm{cmg} / \mathrm{cm}^{\wedge}(-3)$ \\
\hline Aspect ratio & 2.67 \\
\hline Diameter & $12 \mu$ \\
\hline Water absorption & $3.27 \%$ \\
\hline Tensile strength & $67 \mathrm{Mpa}$ \\
\hline elongation at break & $14 \%-46 \%$ \\
\hline
\end{tabular}

TABLE 2: Physical properties of polyester fiber

while for high strength concrete, $1.5 \%$ to $2.5 \%$ is recommended.

\subsection{Polyester Fiber}

The source of manufacturing fiber is different for different fiber. However, the polyester fiber is manufactured from cotton and cotton in Pakistan is in abundance. Hence, it will cost low in price as compared to other fibers. Polyester fiber used in this research work is brought from Bhanero Textile Mill Ltd., Kotri, Jamshoro, Sindh, Pakistan, as shown in Figure 3. Polyester fiber is a synthetic fiber used to control the cracking, bleeding, and segregation and improve the tensile strength and flexural strength higher than compressive strength. Besides, addition of polyester fiber in convention concrete showed a great increment in the strength than the polypropylene fiber [15]. In his research, we used $32 \mathrm{~mm}$ fiber because the availability of polyester fiber in the industry is in huge quantity. The main physical properties of polyester fiber are given in Table 2.

\subsection{Mix Design}

Through DOE mix design method, based on material testing results (cement, fine aggregate crush aggregate), we designed a mix proportion having desired compressive strength of $60 \mathrm{MPa}$ at 28 days of curing with 75 to $180 \mathrm{~mm}$ slump. The final mix design ratio for HSC was found to be 1:1.48:2.0 at w/c ratio, 0.33 and fix dosage of super plasticizer $1.2 \%$ (by weight of cement). The high strength concrete is made by a mixer machine with the appropriate material, as mentioned in Table 3.

\section{Test}

\subsection{Workability}

Workability is defined as "the ease with which concrete can be mixed, compacted, transported, placed and finished ". It means workable concrete denotes the concrete which exhibits very little internal friction between particles of concrete. Many factors which affects the workability property of concrete include water content, mix proportion, size of aggregate, shape of aggregate, surface of texture, grading of aggregate and use of admixture [13]. The slump test will be performed to examine the workability of fresh concrete. In this method of slump test, the apparatus Frustum Cone was used having dimensions of base diameter, top diameter, height of cone as $100 \mathrm{~mm}, 200 \mathrm{~mm}, 300$ $\mathrm{mm}$, respectively. The other tools used included a rod (16 $\mathrm{mm}$ diameter and $60 \mathrm{~cm}$ length), a smooth flat plate/tray and a measuring scale.

Different percentage of poly ester fiber was added in HSC to check its effect on workability property of HSC. There were four mixes designed with polyester fiber content varying from $(0.2 \%, 0.3 \%, 0.4 \%$ and $0.5 \%$ ) by weight of cement in HSC. With these mixes of fresh concrete, the workability test was conducted by slump cone based on ASTM C-143 [22] requirements. The detail of the mixes is given in Table 4 .

\subsection{Compressive Strength}

Controlled compressive strength of HSC utilized in this research is mentioned in Table 5 .

\section{Results \& Discussion}

A mix design ratio was used to obtain target cubical strength C60 HSC by using maximum coarse aggregate size $20 \mathrm{~mm}$ by using local sand. Table 5 shows the compressive strength of HSC at 3, 7 and 28 days. The fiber quantity was taken in terms of percentage $(0.2 \%, 0.3 \%, 0.4 \%$ and $0.5 \%)$ by the weight of cement which was used as an additive material in HSC. We prepared a homogeneous and uniform mix, so that stuffing and lump caused by fiber can be avoided. The required amount of polyester fibers was added and homogeneously spread by hands during mixing of cement, sand and crushes in mixer machine. The standard slump cone was used to perform the slump test on fresh HSC according to ASTM C 143/C143M98:1998 procedure.

Many factors in the mix design affects the workability of concrete. All the ingredients were cement fineness to the fibers used. From the previous studies, it was observed that the slump loss has a direct/linear relation with percentage of fibers used and the mineral admixture also has a great influence on the workability of concrete mix, as these materials has their ability to absorb water from the concrete mix. To tackle this situation, many researchers are opting for the use of chemical admixtures. In this research, a high-strength concrete was designed for a target mean strength of 


\begin{tabular}{|c|c|c|c|c|c|}
\hline \multirow{2}{*}{$\begin{array}{l}\text { Cement } \\
\left(\mathrm{kg} / \mathrm{m}^{3}\right)\end{array}$} & \multirow{2}{*}{$\begin{array}{l}\text { Fine Aggregate } \\
\left(\mathrm{kg} / \mathrm{m}^{3}\right)\end{array}$} & \multicolumn{2}{|c|}{ Coarse Aggregate } & \multirow{2}{*}{ Water } & \multirow{2}{*}{$\begin{array}{l}\text { Super plasticizer } \\
\text { (HRWR) by weight } \\
\text { of cement }\end{array}$} \\
\hline & & $\begin{array}{l}20 \mathrm{~mm} \\
(40 \%)\end{array}$ & $\begin{array}{l}13 \mathrm{~mm} \\
(60 \%)\end{array}$ & & \\
\hline 480 & 710 & 392 & 588 & 160 & $1.2 \%$ \\
\hline
\end{tabular}

TABLE 3: C60 mix design proportion

\begin{tabular}{|c|c|c|c|c|c|c|c|}
\hline \multirow[t]{2}{*}{ No. } & \multirow{2}{*}{$\begin{array}{l}\text { Polyester Fiber } \\
\text { Content(\%) }\end{array}$} & \multirow{2}{*}{$\begin{array}{l}\text { Cement } \\
\left(\mathrm{kg} / \mathrm{m}^{3}\right)\end{array}$} & \multirow{2}{*}{$\begin{array}{l}\text { Fine Aggregate } \\
\left(\mathrm{kg} / \mathrm{m}^{3}\right)\end{array}$} & \multicolumn{2}{|c|}{$\begin{array}{l}\text { Coarse Aggregate } \\
\left(\mathrm{kg} / \mathrm{m}^{3}\right)\end{array}$} & \multirow{2}{*}{$\begin{array}{l}\text { Superplasticizer (HRWR) } \\
\text { by weight of cement }\end{array}$} & \multirow{2}{*}{$\mathrm{w} / \mathrm{c}$ ratio } \\
\hline & & & & $20 \mathrm{~mm}$ & $13 \mathrm{~mm}$ & & \\
\hline 1.0 & (HSC) $0 \%$ & 480 & 710 & 392 & 588 & $1.2 \%$ & 0.33 \\
\hline 2.0 & $0.2 \%$ & 480 & 710 & 392 & 588 & $1.2 \%$ & 0.33 \\
\hline 3.0 & $0.3 \%$ & 480 & 710 & 392 & 588 & $1.2 \%$ & 0.33 \\
\hline 4.0 & $0.4 \%$ & 480 & 710 & 392 & 588 & $1.2 \%$ & 0.33 \\
\hline 5.0 & $0.5 \%$ & 480 & 710 & 392 & 588 & $1.2 \%$ & 0.33 \\
\hline
\end{tabular}

TABLE 4: Detail of concrete (HSC+Polyester fiber) mix

\begin{tabular}{|c|c|c|}
\hline No. & Days & $\begin{array}{c}\text { Compressive strength of HSC } \\
\text { MPa }\end{array}$ \\
\hline 1.0 & 3 & 48.31 \\
\hline 2.0 & 7 & 51.48 \\
\hline 3.0 & 28 & 63 \\
\hline
\end{tabular}

TABLE 5: Compressive strength of HSC

\begin{tabular}{|c|c|c|}
\hline No. & Description & Slump Value $(\mathbf{m m})$ \\
\hline 1 & HSC $+0 \%$ polyster fiber & 178 \\
\hline 2 & HSC $+0.2 \%$ polyester fiber & 153 \\
\hline 3 & HSC $+0.3 \%$ polyester fiber & 127 \\
\hline 4 & HSC $+0.4 \%$ polyester fiber & 102 \\
\hline 5 & HSC $+0.5 \%$ polyester fiber & 76 \\
\hline
\end{tabular}

TABLE 6: Effect of polyester fiber on slump of HSC

$60 \mathrm{MPa}$ by using polyester fiber. In order to make the mix workable enough, a $1.2 \%$ poly carboxylic ether chemical by the weight of the cement was used. The standard slump test conduct by slump cone on fresh HSC control mix was performed.

The addition of polyester fiber in HSC mix significantly changed the workability properties in the form of reduced bleeding and reduced slump value. The test results indicate that workability of all concrete mixes made with polyester fiber was lower than the control mix. It means with the increase in percentage of polyester fibers, the workability of HSC concrete linearly decreased at fix dosage of super plasticizer and w/c ratio. Slump test results are given in the Table 6 and shown in Figure 4-6.

In the above figure 1 and 2 the effect of polyester fiber on the workability of HSC is plotted. It is evident that with the increasing percentage of polyester fiber, the slump greatly reduced. In the above figures, slump values of different mixes are compared. The maximum value of slump was shown at the control mix with-

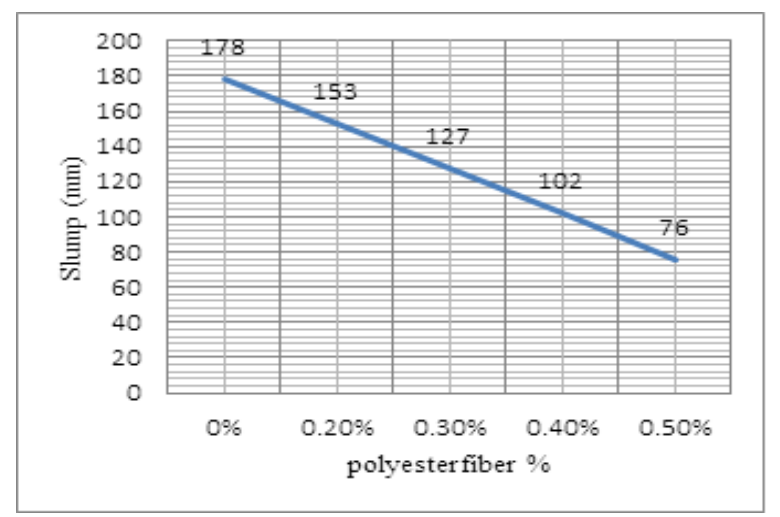

Fig. 4: Effect of polyester fiber on Slump of HSC

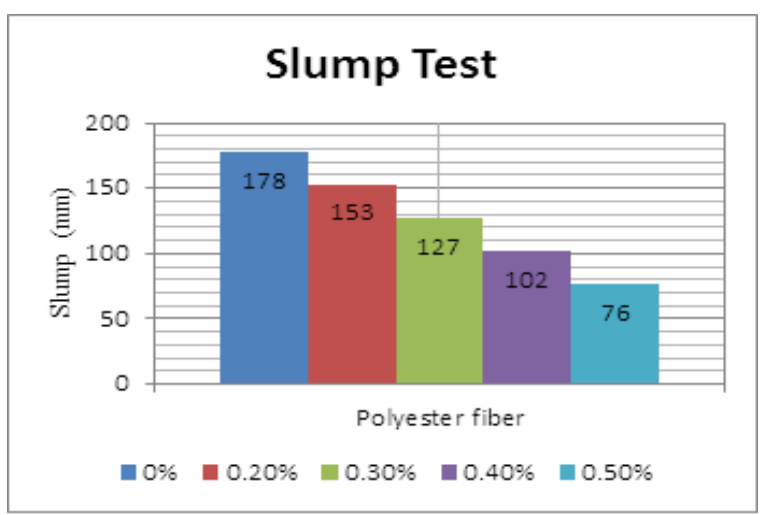

Fig. 5: Effect of polyester fiber on Slump of HSC

out the inclusion of polyester fiber. The inclusion of polyester fiber started from $0,0.2 \%, 0.3 \%$, and $0.4 \%$ to $0.5 \%$ of weight of cement and reduced the slump value from 178, 153, 127, 102 to $76 \mathrm{~mm}$ respectively. With the increment of polyester fiber, the slump value decreased within the required design limits which were fixed at a range of $75 \mathrm{~mm}$ to $180 \mathrm{~mm}$.

In Figure 3, a relation between polyester fibers to the 


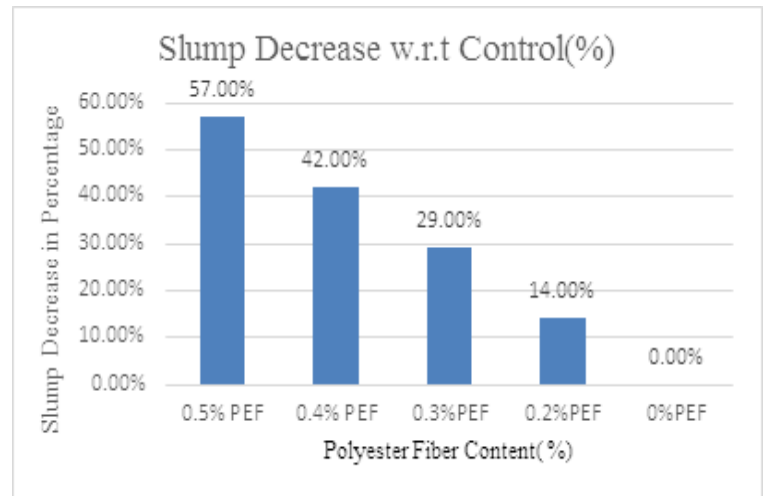

Fig. 6: Effect of polyester fiber on Slump of HSC

slump value is plotted. As we increased the percentage of polyester fiber in $\mathrm{HSC}$, the reduction in the slump also increased in percentage. It was observed that the usage of fiber (0.2 to $0.5 \%)$ decrease workability between $(14 \%$ to $57 \%)$ of HSC. The similar trend of reduction in the slump of normal concrete with the addition of fiber was achieved [10][12][16].

\section{Conclusion}

Our experimental research concluded the following points.

1) HSC having compressive strength of $63 \mathrm{MPa}$ at 28 days can be prepared by using super plasticizer M/Polyheed 996 polycarboxylic ether.

2) Addition of polyester fiber content in HSC from $0.2 \%-0.5 \%$ can reduce the slump by $14 \%-57 \%$.

3) Addition of polyester fiber content in HSC controlled the bleeding and shrinkage of HSC.

\section{References}

[1] I. Kovacevic and S. Dzidic, "High-Strength Concrete (HSC) Material for High-Rise", 2018.

[2] ACI Committee 363, "State-of-the-Art Report on HighStrength Concrete," Am. Concr. Inst., vol. 92, no. Reapproved, p. 55, 1997.

[3] European Committee for Standardization (CEN), "BS EN 206-1:2000 Concrete - Part 1: Specification, performance and conformity," Br. Stand., vol. 3, p. 74, 2000.

[4] M. Salem, S. Alsadey, and M. Johari, "Effect of Superplasticizer Dosage on Workability and Strength Characteristics of Concrete," IOSR J. Mech. Civ. Eng., vol. 13, no. 04, pp. 153-158, 2016.

[5] A. R., "Effect of Mineral Admixtures on Characteristics of High Strength Concrete," Int. J. Res. Eng. Technol., vol. 04, no. 02, pp. 610-614, 2015.

[6] M. M. A. Moid and A. P. W. Rahul, "Study of High Strength Fiber Reinforced Concrete for M80 Grade by using Different Types of Steel Fibre Study of High Strength Fiber Reinforced Concrete for M80 Grade by using Different Types of Steel Fibre People's Educational Society Engineering Colleg," no. February 2017, 2016.
[7] M. M. Hilles and M. M. Ziara, "Mechanical behavior of high strength concrete reinforced with glass fiber," Eng. Sci. Technol. an Int. J., vol. 22, no. 3, pp. 920-928, 2019.

[8] P. Kaur and M. Talwar, "Different types of Fibres used in FRC," Int. J. Adv. Res. Comput. Sci., vol. 8, no. 4, pp. 2015-2018, 2017.

[9] D. Id, "ACI 212 . 3R-10 Report on Chemical Admixtures for Concrete," vol. 28, pp. 0-15, 2015.

[10] A. Hasan, N. Maroof, and Y. Ibrahim, "Effects of Polypropylene Fiber Content on Strength and Workability Properties of Concrete," Polytech. J., vol. 9, no. 1, pp. 7-12, 2019.

[11] A. D. De Figueiredo and M. R. Ceccato, "Workability analysis of steel fiber reinforced concrete using slump and ve-be test," Mater. Res., vol. 18, no. 6, pp. 1284-1290, 2015.

[12] P. Jean, P. Gleize, and H. Ramos, "Mechanical Properties of Recycled PET Fibers in Concrete Mechanical Properties of Recycled PET Fibers in Concrete," no. August, 2012.

[13] M. A. Pathan, R. Ahmed, and M. Maira, "Study of Coarse Aggregate Characteristics on Strength Properties of High Performance Concrete Using Chemical Admixtures," vol. 2657, no. May, pp. 33-38, 2019.

[14] S. Ali, H. Kumar, S. H. Rizvi, M. S. Raza, and J. K. Ansari, "Effects of Steel Fibers on Fresh and Hardened Properties of Cement Concrete," Civ. Environ. Eng. Reports, vol. 30, no. 3, pp. 186-199, 2020.

[15] M. N. Khan and S. Singh, "Use of Discrete Fiber in Road Pavement Use of Discrete Fiber in Road Pavement," no. August, 2020.

[16] V. S. Mathda and M. H. K. Khaire, "Study of Effects of Polyester Fibers on Compressive Strength of Concrete," vol. 4, no. I, pp. 53-56, 2016.

[17] A. T. P. J, S. Sreekumar, and A. V Aparna, "Strength Characteristic Study of Polyester Fiber Reinforced Concrete," vol. 6, no. 06, pp. 1-7, 2018.

[18] K. Shantveerayya and V. Nikkam, "An Experimental Study on the Properties of Glass Fibre Reinforced and Ground Granulated Blast Furnace Slag Concrete," Int. J. Civ. Eng., vol. 3, no. 3, pp. 14-19, 2016.

[19] I. Patel and C. D. Modhera, "Study Effect of Polyester Fibres on Engineering Properties of High Volume Fly Ash Concrete," J. Eng. Res., no. I, pp. 159-166, 2011.

[20] S. Pal, M. K. Mishra, and V. Pandey, "Effects of Surface Treatment of Polyester," pp. 8341-8350, 2016.

[21] R. You, "Effect of Early Strength, Retarding and Slumpretaining Components of Polycarboxylic Acid Admixture on Workability of Fresh Concrete," IOP Conf. Ser. Mater. Sci. Eng., vol. 631, no. 2, 2019.

[22] C. C. Test and B. Statements, "Standard Test Method for Slump of Hydraulic-Cement Concrete 1," pp. 4-7, 2019. 